\title{
IE MONDE FLAMAND DANS FASTES D'ENFER \\ DE MICHEL DE GHELDERODE
}

Michel de Ghelderode est un auteur dramatique belge, d'origine flamande. Son théâtre est imprégné par le monde flamand, surtout par celui du Moyen Age et du seizième siècle.

Une pièce comme les "Fastes d'Enfer", est pleine de références au paysage flamand, à la ville, à la société, aux fléaux qui se sont abattus sur les villes, aux rites de la société et aux visions de ses artistes.

La Flandre est une contrée plate, couverte de marécages.l C'est le pays de la mer, du sable et Jan in Eremo, la figure principale des "Fastes" est "fils de la mer et du sable."2 Une épaisse brume maritime couvre souvenţ le pays, elle donne alors un aspect fantômatique au paysage. 3 Quand la tempête fait rage, il arriye que la mer envahisse les terres. 4 Le ciel est alors ténébreux, sinistre, des éclairs d'un blanc spectral en déchirent l'obscurité. 5 En été, à l'intérieur des terres, I'eau stagnante des nombreux marécages exhale d'abominabies odeurs 6 et " 1 'air est lourd, vibrant de mousm tiques."7

Jan in Eremo, nous dit-on, a été éduqué à I'abbaye des Dunes. 8 L'abbaye des Dunes se trouye, à Coxyde, actuellement plage de villégiature. I'abbaye a été exhuinée des sables. il y a quelques années. De sa splendeur passée, il ne reste
que la base des murs en brique. Cette abbaye a été très riche et puissante, ses possessions s'étendaient le long de la mer et assez loin dans les terres. Sa richesse provenait de ses pêcheries et de nombreuses fermes 9 dont il existe encore, disséminées en Flandre, d'énormes granges.

Dans "Fastes d'Enfer " on trouve des allusions à la ville flamande. Le Vieux Bourgio est la partie de la ville construite pendant le Moyen Age. Aux quinzième et seizième siecles, beaucoup de villes se sont agrandies grâce à la paix du régime bourguignon et au développement du commerce. Ces agrandissements se sont effectués hors des murs de la ville 
et ils en ont épousé les contours extérieurs.

Les tours des églises dominent la ville flamande.ll $\mathrm{Ce}$ sont d'énormes tours carrées qui ont servi de vigie, de phare. Les cloches annonçaient les événements, 12 donnaient 1 'heure, dirigeaient les bateaux. Avant d'être placées, elles étaient solennellement baptisées, avaient parrain et marraine: "Klank, celle de Sainte-Walburge! Son nom est Maria ..."13

I'autre bâtiment d'importance dans la ville flamande était la halle. Les halles, sont des marchés couverts et généralement de très beaux édifices comme celles d'Ypres. celles de Louvain. 14

Ia ville flamande est administrée par un bourgmestre. Aux quinzieme et seizième siecles, c'était un riche bourgeois qui jouissait de beauçoup d'autorité. 15 Dans sa tâche, il était aidé par des, échevins, bourgeois eux aussi, car seule la bourgeoisie était représentée.16

Chaque métier était organisé et avait à sa tête un doyen.17 Les corporations des bouchers et des foulons étaient trés importantes car elles représentaient les deux "industries" principales. 18 leurs "armées. 20 Les villes flamandes ont trés mal supporté les diverses dominations étrangeres et leur histoire est. pleine de révoltes contre 1 'envahisseur. 21

A côté de la population bourgeoise vivait un prolétariat souvent sans travail qui était attiré par le luxe de la ville. Le peuple mangeait rarement à sa faim, les guerres, les razzias ont plus d'une fois créé de terribles famines: "On dressait à la halle des autels portant de croulants holocaustes de viandes pourpres, on suspendait des boeufs énormes, des troupeaux ....Ho! Krakenbus, je 
voyais ça, et le peuple maigre, maigre à faire peur..." 22

Une autre classe à part était celle des juifs. Au Moyen Age, 1!'Eglise interdisait aux chrétiens 1'état de banquier. Les juifs pratiquaient donc ce métier. S'ils vivaient en dehors de la soeiété flamande, ils étaient cependant acceptés, étant nécessaires au commerce.23

Les villes flamandes connurent une paix relative au début du seizième siècle, mais elles eurent à vaincre un ennemi terrible et implacable: la peste. Les conditions climatiques, l'ignorance médicale faisaient de la peste un fléau impossible à combattre. La population était décimée, les traquaux suspendus et la famine achevait l'oeuvre de la peste. ${ }^{24}$ Ceux qui le pouvaient quittaient la ville en toute hâte. ${ }^{25}$ Pour empêcher la peste de s'étendre. on brûlait $y_{26}$ corps, le linge, les meubles ayant appartenu aux victimes. 26 İ peste, était considérée comme un châtiment venu de Dieu. 27 En général, un changement des conditions climatiques enrayait l'épidémie. "Les brumes jaunes se disloquaient, le ciel pur apparaissait et lievent, le large
vent bleu chassait les miasmes mortels. 280

Des processions, certaines établies à date fixe, égayaient la ville. Elles étaient et le sont encore de deux genres: les unes profanes, les autres religieuses.

Ia plus célébre procession profane est 1'ommegang. 29 Dans 1 ! Ommegang paraisiont tous les conps de métiers, vêtus de leurs plus beaux atours. Les porte-drapeau exécutent des jeux, une cavalcade historiọue et légendaire défile. Des géants comme celui d'Anvers, 30 des dragons sont à nouveau vaincus par un héros. C'est une procession haute en couleurs et elle est animée par des joueurs de tambour. de trompette.

Ia procession religieuse est un événement important dans la vie urbaine. On sort en procession pour demander le beau temps, la fin d'une guerre, d'une épidémie ou pour 
fêter un saint. Les pénitents sont vêtus de longuesrobes de bure, ils ont la tête couverte d'une cagoule, 31 Ils vont pieds nus, ils portent une lourde croix et. parfois, des chaînes: les mysticismes flamand et espagnol se sont rencontrés au cours du seizieme siècle. 32 L L ${ }_{3}$ plus célébré pro-

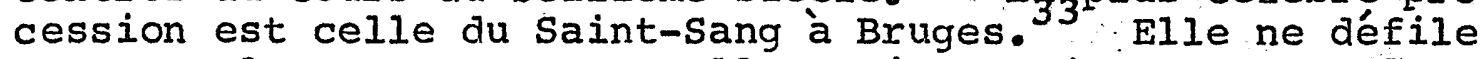
que tous les quatre ans et elle attire toujours une foule énorme.

Certaines images dans les "Fastes d'Enfer" s'apparentent aux visions de peintres comme Hieronymus Bosch ou Pierre Breugel le vieux. Des expressions comme "allongez vos blairs, " 34 "vous áont le groin flaire la truffe." 35 associent l'homme à l'animal. Ces êtres mi-animaux; mi-humains sont représentés dans un tableau comme la "Tentation de Saint Antoine" de Bosch: 36 on trouve des images comme "Ravale ton lavement;" 37 "Après, vous pourriez voltiger dans les airs comme une marionnejtte et retomber, empalé par le Eondement, sur un piquet. "38 Ces images s'apparentent aux supplices qu'attendent. 1 es damnés dans le "Jugement Dernier" de Bosch, par exemple. 39

Nous n'étudierons pas ici le dernier aspect flamand des "fastes." Les influences de la langue flamande sur le langage de Ghelderode feront l'objet d'un autre article.

"Fastes d'Enfer," seuvre hallucinante de Ghelderode; est donc une pièce profondément influencée par le monde flamand. Nous remarquons qu'il $n^{\prime} y$ a aucune indication précise du temps: les "Fastes" se passent "en Flandre d'autrefois. 40 on $y$ releve des élements du Moyen-Age et du seizième siècle, mis sans aucune chronologie. Ce cadre flamand parce qu'imprécis et flou, en est plus magique, plus mystérieux. C'est le monde rêvé par le grand poète qu'était Ghelderode. 
NOTES

${ }^{1}$ Jacques G. Benay and Reinhard Kuhn. Panorama du Théâtre Nouveau, Le thêatre des enfers. New York: AppletonCentury-Crofts. 1967, p. 90, 1. 8 .

2p. 96, 1. 26 .

$3 \mathrm{p} .96,1.18$.

$4 \mathrm{p} .97,1,27$.

5p. 102, 11. 22-26.

7 p. $90,1.29$.

$8 \mathrm{p} .81,1.25$.

9 p. $96,1,23$.

$10 \mathrm{p}, 97,1,4$.

$11 \mathrm{p} .76,11.3-4$.

$12 \mathrm{p} .122,1.5$.

$13 \mathrm{p}, 75,11.28-29$.

$14 \mathrm{p} .70,1.12$.

$15 \mathrm{p}, 81,1.31 ; \mathrm{p}, 82,11,1-5$.

$16 \mathrm{p} .82,1.9$.

$17 \mathrm{p} .120,1.61$.

$18 \mathrm{p} .100,1.1$.

$19 \mathrm{p} .108,1.14$.

20 p. $81,11,2-3$.

$21 \mathrm{p} \cdot 90,1.15$.

$22 \mathrm{p} .70,11 \cdot 11-15$.

24 p. $91,11.6-8$.

25. 98-99.

25. 98, 11. 12-13.

$27 \mathrm{p}, 98,11.14-15$.

27p. 81, 11. 7-8.

28 p. 98, 11. 31-32; p. 99, 1. 1.

$29 \mathrm{p} .82$, 11. 13-14.

30 "Antwerpen" en flamand.

31 p. 82, 11. 2-3.

$32 \mathrm{p}$. 87, 11. 18-19.

33 "Brugge" en flamand.

$34 \mathrm{p} .83,1.14$.

$35 \mathrm{p} .83,1.18$. 
36. Bruxelles; Musées Royaux des Beaux-Arts de Belgique, inv. no 3032 .

37 Benay et Kuhn, op. cit.. p. 83, 1. 23.

38 Ibid.. p. 92, 11. 27-30.

39 Bruges, Stedelijck Museum voor Schone Kunsten, Groeningemuseum. inv. no 208.

40 Benay et Kuhn, op. cit.. p. $69,1.1$. 